Arq. Bras. Med. Vet. Zootec., v.59, n.2, p.530-532, 2007

\title{
Comunicação
}

[Communication]

\section{Condrossarcoma primário de língua em cão}

[Primary chondrosarcoma in the tongue of a dog]

\author{
A.E. Silva ${ }^{1}$, E.L.T. Moreira ${ }^{1}$, N.M. Ocarino $^{2}$, A.L. Franco ${ }^{3}$, A.P. Santos ${ }^{3}$, \\ T.S. Souza ${ }^{3}$, R. Serakides ${ }^{2 *}$ \\ ${ }^{1}$ Escola de Medicina Veterinária - UFBA - Salvador, BA \\ ${ }^{2}$ Escola de Veterinária - UFMG \\ Caixa Postal 567 \\ 30123-970 - Belo Horizonte, MG \\ ${ }^{3}$ Aluno de graduação - EMV-UFBA - Salvador, BA
}

O condrossarcoma é uma neoplasia maligna mesenquimal, na qual, as células cartilaginosas do tumor produzem quantidades variáveis de matriz condróide e matriz fibrilar neoplásicas (Thompson e Pool, 2002). O condrossarcoma pode se desenvolver primariamente tanto no sistema esquelético (Thompson e Pool, 2002) quanto em sítios extra-esqueléticos (Miller et al., 2005; Romanucci et al., 2005). Pode ser classificado em dois subtipos: subtipo mixóide, diagnosticado com mais freqüência em condrossarcomas esqueléticos e subtipo mesenquimal que embora raro, é mais frequentemente diagnosticado em sítios extraesqueléticos. (Casadei et al., 1991). Em medicina veterinária, o condrossarcoma extra-esquelético é um tumor raro de tecido mole (Thompson e Pool, 2002) embora já relatado em órgãos como pericárdio, baço e pele (LaRock et al., 1997; Miller et al., 2005; Romanucci et al., 2005). Contudo, na literatura consultada, somente um caso de condrossarcoma de língua foi descrito em eqüino (Wilson e Anthony, 2007) ao contrário da medicina humana em que alguns condrossarcomas de base de língua já foram descritos (Forman, 1967). Assim, este artigo consiste no primeiro relato de condrossarcoma mesenquimal de base de língua em cão.

Uma cadela da raça Boxer de 10 anos de idade, foi encaminhada morta ao hospital veterinário para a realização de necropsia sem histórico

Recebido em 20 de julho de 2006

Aceito em 3 de janeiro de 2007

E-mail: serakide@dedalus.lcc.ufmg.br clínico. Ao exame post-mortem, foram observadas caquexia e mucosas cianóticas. Na base dorsal da língua foi observada uma massa neoplásica medindo $6,0 \times 5,5 \times 3,0 \mathrm{~cm}$ com superfície irregular, de aspecto multinodular e com área central ulcerada. A neoplasia, brancoamarelada firme, infiltrava-se na musculatura da língua. Ao corte, foram observadas áreas multifocais de hemorragias e áreas esbranquiçadas que rangiam. A neoplasia estava distante da oro-faringe e dos ossos hióides cerca de quatro centímetros sem envolvimento dessas estruturas (Fig. 1A). Os pulmões estavam congestos e com edema intenso e o coração apresentava dilatação bilateral das câmaras ventriculares. Rins, fígado e sistema nervoso central (SNC) estavam congestos. Não foram observados sítios de metástases.

À histologia, foi observada, na submucosa da língua, neoplasia pouco delimitada e infiltrativa formada predominantemente por células cartilaginosas neoplásicas pouco diferenciadas com discreta formação de matriz cartilaginosa. As células eram arranjadas em ilhas ou em ninhos separadas em lóbulos por tecido conjuntivo fibroso (Fig. 1B). A neoplasia infiltrava-se na musculatura do órgão $\mathrm{e}$ projetava-se em direção ao epitélio que apresentava área focal de ulceração. $\mathrm{O}$ núcleo das células neoplásicas era pleomórfico e hipercromático; algumas vezes, era evidente a presença de lacunas cartilaginosas preenchidas por mais de um núcleo (Fig. 1C). Em algumas 


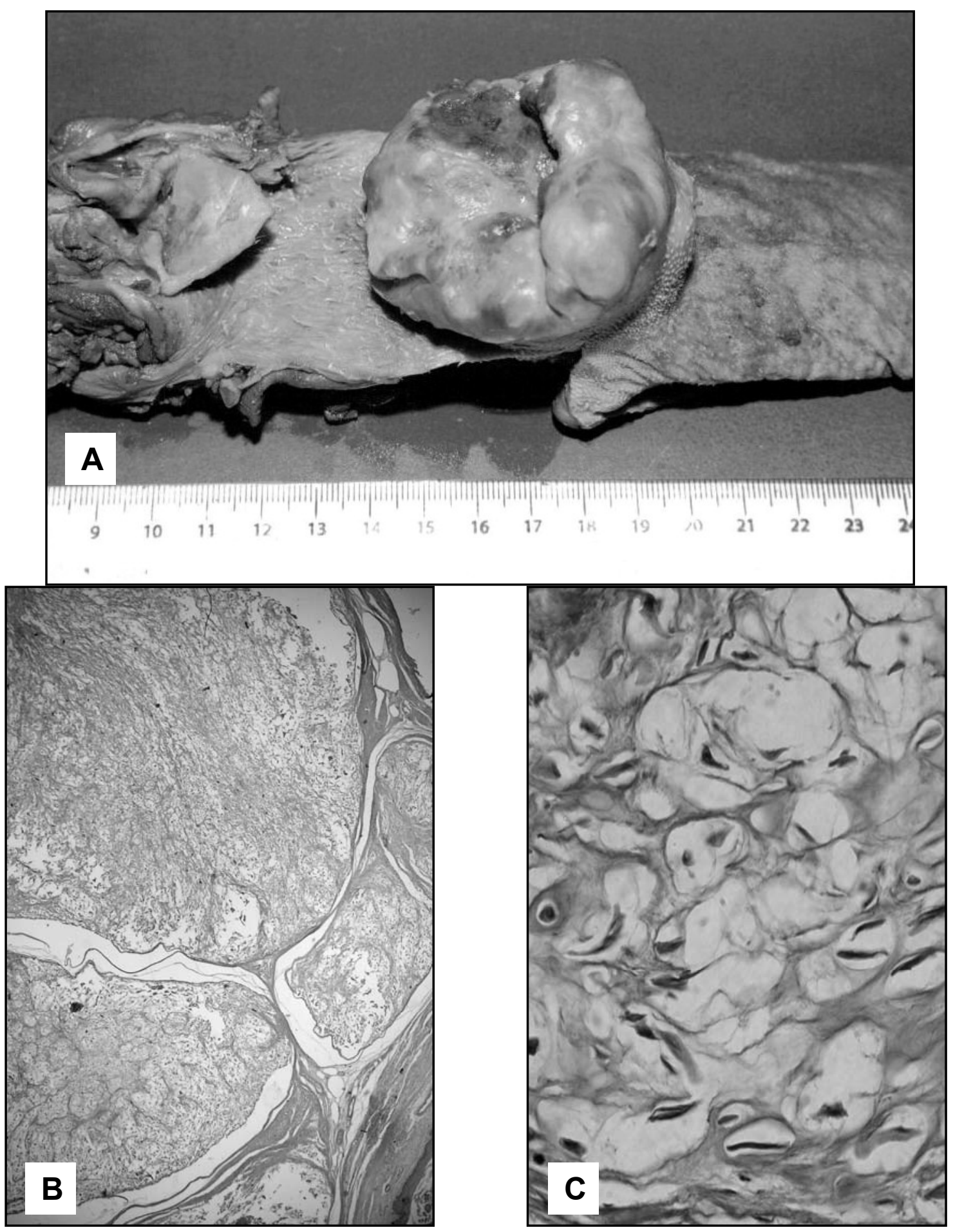

Figura 1. Cão, condrossarcoma de base de língua. A) Massa neoplásica de 6,0×5,5×3,0cm com superfície irregular, de aspecto multinodular distante da oro-faringe e dos ossos hióides. B) Células neoplásicas arranjadas em ninhos separadas em lóbulos por tecido conjuntivo fibroso. HE, 120×. C) Condrócitos neoplásicos com núcleos pleomórficos, hipercromáticos e células binucleadas (seta). HE, $7,5 \times$. 
regiões foi possível observar células mesenquimais primitivas indiferenciadas; e o índice mitótico era baixo. No centro de alguns lóbulos foram observadas áreas de necrose, mineralização e extensas áreas de hemorragia com presença de hemossiderina e células neoplásicas no interior de vasos sangüíneos. De acordo com as características histológicas, foi firmado o diagnóstico de condrossarcoma mesenquimal extra-esquelético.

O condrossarcoma extra-esquelético pode ser classificado nos subtipos mixóide ou mesenquimal que, embora raro, é mais frequentemente diagnosticado em sítios extraesqueléticos (Casadei et al., 1991). Neste caso, o diagnóstico de condrossarcoma mesenquimal foi firmado devido à presença de células mesenquimais malignas pouco diferenciadas, arranjadas em ilhas ou difusamente distribuídas. Além disso, não havia em nenhuma das secções histológicas áreas de transformação mixóide, à semelhança do que é observado no subtipo mixóide. Embora a etiologia do condrossarcoma extraesquelético não seja conhecida, suspeita-se que células mesenquimais primitivas multipotentes presentes em vários sítios do organismo possam sofrer diferenciação maligna em cartilagem (Nesi et al., 2000). Na medicina veterinária o tratamento para condrossarcoma extraesquelético é a excisão cirúrgica radical (Thompson e Pool, 2002).

O quadro de caquexia provavelmente ocorreu devido à presença da massa neoplásica na base da língua dificultando a mastigação e a deglutição do alimento; a provável causa mortis do animal foi um quadro de insuficiência cardíaca causada pela dilatação do órgão, o que justifica as alterações observadas nos pulmões, fígado, rins e SNC.

Palavras-chave: cão, condrossarcoma, língua

\section{ABSTRACT}

A 10 year old female Boxer was taken dead to veterinary hospital for a necropsy without any clinical history, showing a growth on the dorsal part of the tongue. Based on the histopathological findings mesenchymal chondrosarcoma was diagnosed. This report describes the first case of chondrosarcoma on the base of the tongue in veterinary medicine.

Keywords: dog, chondrosarcoma, tongue

\section{REFERÊNCIAS BIBLIOGRÁFICAS}

CASADEI, R.; RICCI, M.; RUGGIERI, P. et al. Chondrosarcoma of the soft tissues: Two different subgroups. J. Bone Joint Surg. Br., v.73-B, p.162-168, 1991.

FORMAN, G. Chondrosarcoma of the tongue. Br. J. Oral Surg., v.4, p.218-221,1967.

LAROCK, R.G.; GINN, P.E.; BURROWS, C.F. et al. Primary mesenchymal chondrosarcoma in the pericardium of a dog. J. Vet. Diagn. Invest., v.9, p.410-413, 1997.

MILLER, J.M.; WALSHAW, R.; BOURQUE, A.C. Primary splenic mesenchymal chondrosarcoma in a dog. Can. Vet. J., v.46, p.163-165, 2005.

NESI G.; PEDEMONTE E.; GORI, F. Extraskeletal mesenchymal chondrosarcoma involving the heart: report of a case. Ital. Heart J., v.6, p.435-437, 2000 .

ROMANUCCI, M.; BONGIOVANNI, L.; PETRIAZZI, L. et al. Cutaneous extraskeletal mesenchymal chondrosarcoma in a cat. Vet. Dermatol., v.16, p.121-124, 2005.

THOMPSON, K.G.; POOL, R.R. Tumors of bones. In: MEUTEN, D.J. ed. Tumors in domestic animals, 4.ed. Ames: Iowa State, 2002, p.245-317 